\title{
Amadou Hampâté Bâ y la reconstrucción de la identidad africana a través de la oralidad
}

\author{
Teresa ÁlVAREZ MARTÍNEZ \\ Universidad de Cádiz \\ Departamento de Filología Francesa e Inglesa \\ teresa.alvarezmartinez@alum.uca.es
}

Recibido: $28 / 10 / 2013$

Aceptado: 19/02/2014

\begin{abstract}
Resumen
Amadou Hampâté Bâ (Bandiagara, 1901 - Abiyán, 1991) fue una de las personalidades más relevantes del panorama cultural africano del siglo XX. Defensor y divulgador de la cultura e historia africanas, su trabajo en el seno del Consejo Ejecutivo de la Unesco permitió lanzar importantes campañas de conservación del patrimonio inmaterial de África del Oeste. Hampâté Bâ fue uno de los primeros etnólogos africanos que se dedicó a estudiar y a difundir su cultura desde dentro, huyendo así de los prejuicios derivados del colonialismo e interpretando su cultura como una entidad viva, operativa y fundamental para la reconstrucción de la identidad africana.
\end{abstract}

Palabras clave: Amadou Hampâté Bâ, África, oralidad, cultura, identidad, colonialismo.

\section{Amadou Hampâté Bâ et la reconstruction de l'identité africaine à travers}

\section{l'oralité}

\section{Résumé}

Amadou Hampâté Bâ (Bandiagara, 1901 - Abidjan, 1991) fut une des personnalités les plus marquantes du panorama culturel africain du $\mathrm{XX}^{\mathrm{e}}$ siècle. Défenseur et illustrateur de la culture et de l'histoire africaine, son travail au sein du Conseil Exécutif de l'Unesco permit de lancer d'importantes campagnes de conservation du patrimoine immatériel de l'Afrique de l'Ouest. Hampâté Bâ fut un des premiers ethnologues qui se consacra à l'étude et à la diffusion de sa culture de l'intérieur, en évitant les préjugés coloniaux et en interprétant sa culture comme une entité vivante, opérative et fondamentale pour la reconstruction de l'identité africaine.

Mots clés: Amadou Hampâté Bâ, Afrique, oralité, culture, identité, colonialisme.

\section{Amadou Hampâté Bâ and the Reconstruction of the African Identity Through Orality}

\begin{abstract}
Amadou Hampâté Bâ (Bandiagara, 1901 - Abiyán, 1991), writer, ethnologist and historian, was one of the most relevant figures in African culture of the twentieth century. Defender and disseminator of the history and culture of Africa, his work as a member of the Executive Council of UNESCO allowed him to launch influential campaigns to conserve the immaterial cultural patrimony of West Africa.
\end{abstract}


Hampâté Bâ was one of the first African ethnologists dedicated to the study and dissemination of African culture. His interpretation of the culture as a living entity without the prejudices deriving from colonialism was fundamental to the reconstruction of the African identity.

Key words: Amadou Hampâté Bâ, Africa, orality, culture, identity, colonialism.

\section{Referencia normalizada}

Álvarez Martínez, T. (2014). "Amadou Hampâté Bâ y la reconstrucción de la identidad africana a través de la oralidad". Thélème. Revista Complutense de Estudios Franceses, Vol. 29, Núm. 2: 265280. http://dx.doi.org/10.5209/rev_THEL.2014.v29.n2.43269

La obra de Hampâté Bâ presenta un interés ejemplar, ya que puede ilustrar como pocas una de las cuestiones fundamentales de la literatura negro-africana, a saber, las condiciones históricas de emergencia de una palabra africana. El recorrido de la obra de Hampâté Bâ puede ser interpretado como una lucha por ocupar un lugar significativo dentro del campo cultural, lugar al que el autor habría tenido acceso dentro de la estructura social a la que pertenecía si no hubiera existido la ocupación francesa y no se hubiera impuesto el régimen político y administrativo colonial. Partiendo de una posición periférica tanto en el campo del saber africanista como en el de la literatura, Hampâté Bâ logra alcanzar un estatus como autor y, al mismo tiempo, una autoridad científica en el campo de la etnología africana. La trayectoria del autor es un recorrido excepcional en el que un subalterno (Spivak, 1988) consigue batirse por la defensa de su propia cultura de origen y hacer oír su voz dentro de la república mundial de las letras (Casanova, 1999).

La obra de Hampâté Bâ se inserta en una sociedad africana que todavía no ha perdido sus señas de identidad propias pero que está siendo sometida desde el exterior a un proceso de desvalorización cultural que cuestiona toda su estructura social. El régimen colonial francés en África Occidental Francesa da lugar a una realidad social cambiante y ambigua en la que Hampâté Bâ se tiene que situar como autor. Así, la obra de Hampâté Bâ se encuentra a caballo entre realidades dispares, $\mathrm{y}$, hasta cierto punto, encontradas, que conforman el contexto vital del propio autor: la oralidad y la escritura, la reproducción del relato oral y la creación personal, la biografía y la escritura novelesca. Al igual que la sociedad que lo rodea, su obra navega entre realidades ambiguas y fluctuantes y, tal y como afirma Durand, refleja la búsqueda y afirmación de una identidad propia que ha de dar entrada y equilibrar realidades muy diferentes:

Le jeune Amadou sera le fils à la fois d'une tradition orale immémoriale, et de la greffe, plus problématique, de l'école française et de la culture écrite sur des traditions endogènes restées longtemps inaltérées. Toute sa trajectoire intellectuelle et personnelle témoigne de cette ambivalence qui le conduit tantôt à mettre l'accent sur la permanence du fond africain, tantôt sur les bouleversements que provoque l'ouverture, plus forcée que consentante, sur l'Histoire "mondiale" [...] (Durand, 2003: 10). 
Desde su infancia, Amadou Hampâté Bâ está en contacto con la que Derive define como civilización de la oralidad (2008: 17-35), entorno en el que el autor crece y forja su personalidad. Hampâté Bâ nace a principios de 1901 en Bandiagara, antigua capital del imperio peul de Macina, en el seno de una importante familia noble emparentada directamente con la realeza. Hace tan sólo ocho años que los franceses han conquistado la región y el proceso de aculturación que los colonizadores llevan a cabo tras la conquista militar está solamente en sus inicios. Como el propio Hampâté Bâ afirma en numerosas ocasiones, su infancia transcurre en la escuela del verbo (Bâ, 1991), entorno en el que escucha por primera vez las versiones reducidas de los cuentos iniciáticos peuls que luego publicará en su madurez.

Destinado a heredar de su padre adoptivo, Tidjani Tiam, la jefatura de la región de Louta, el pequeño Amadou ve cómo su destino se trunca cuando la administración colonial condena al príncipe Tijdani a ser encarcelado en el penal de Bougouni ${ }^{1} \mathrm{y}$ todos sus bienes son confiscados. Educado a partir de los siete años en la escuela coránica, a la edad de doce años Hampâté Bâ regresa junto a su familia a Bandiagara y es reclutado de oficio para entrar en la escuela colonial francesa ${ }^{2}$, centro en el que completa su escolaridad básica antes de ser enviado a la escuela regional de Djenné.

Tras obtener el certificado de estudios indígena, Hampâté Bâ supera los exámenes de admisión de la selectiva Escuela Normal William Ponty de Goré, sin embargo, el destino de Hampâté Bâ vuelve a truncarse por segunda vez ya que Kadidja, su madre, no está de acuerdo en que su hijo continúe estudiando la lengua

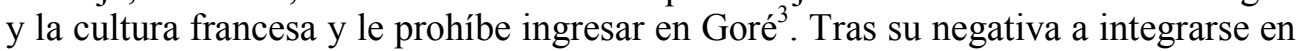
la Escuela Normal, Hampâté Bâ es castigado por la administración colonial a ocupar un puesto de "écrivain à titre essentiellement précaire et révocable" (Bâ, 1991: 503) en Wagadugú, uno de los puestos más alejados de la colonia. Durante este largo viaje desde Dakar a Wagadugú el joven Hampâté Bâ comienza a consignar por escrito todos los relatos orales que consigue escuchar a través de los

\footnotetext{
${ }^{1}$ Bougouni es una pequeña población situada al sur de Bamako, a más de setecientos kilómetros de Bandiagara, en medio de una región de mayoría bambara. La administración colonial determinó que el príncipe defenestrado sería exiliado de Bandiagara y cumpliría condena en esta prisión para evitar los levantamientos populares en su apoyo (Bâ, 1991: 133).

${ }^{2}$ El alumnado de estos centros estaba formado principalmente por los hijos de jefes o de notables que eran obligados a llevar a sus descendientes a la escuela, de esta manera la administración colonial francesa lograba la fidelidad de sus familias a la causa colonial, ya que sus hijos quedaban retenidos bajo el poder de la administración francesa: la primera escuela colonial creada en 1854 en Kayes por Faidherbe fue llamada "Escuela de rehenes", dicha escuela fue trasferida a Bamako en 1908 y su nombre fue cambiado al de "Escuela de hijos de jefes" (Bâ, 1991: 492).

${ }^{3}$ Según cuenta el propio Hampâté Bâ (1991: 501-502), un peul nunca se atrevería a desobedecer una orden materna, de manera que, aunque sabe que esta decisión le va a causar problemas, no se plantea cuestionarla.
} 
maestros de la palabra que va encontrando a lo largo de su camino. Estos escritos son el comienzo de una ingente colección de documentos ${ }^{4}$ que Hampâté Bâ enriquecerá durante toda su vida.

Con 21 años Hampâté Bâ ocupa su primer destino como funcionario colonial en Wagadugú, y a partir de este momento, comienza una larga carrera dentro de la administración que culminará con su destino en el IFAN ${ }^{5}$ al que llega en 1942 para trabajar bajo las órdenes de Théodore Monod. El Instituto Francés de África Negra le permite a Hampâté Bâ dedicarse por completo a la que había sido una de sus pasiones desde su juventud, la compilación y el estudio del patrimonio inmaterial de los distintos pueblos que habitan el territorio del Sudán francés. Además, su nuevo entorno de trabajo es una importante plataforma desde la que Hampâté Bâ va a poder acceder al mundo de la publicación y al círculo de etnólogos y antropólogos europeos que comienzan a interesarse por la cultura de los pueblos del África del Oeste. Este será el principio de una fructífera trayectoria como científico y como escritor, que le llevará a dirigir el IFAN de Bamako en la víspera de las independencias y a ocupar un puesto en el Consejo Ejecutivo de la Unesco a partir de 1960.

Desde su adolescencia, Hampâté Bâ es consciente del interés que despierta la literatura oral africana, en especial los cuentos, entre los etnólogos europeos. Como podemos leer en sus memorias (Bâ, 1991: 346), el pequeño Hampâté Bâ tiene la ocasión de conocer en 1912 a François-Victor Equilbecq, funcionario colonial destinado en Senegal y autor de una de las primeras recopilaciones de cuentos provenientes de la literatura oral africana ${ }^{6}$. Equilbecq obtenía los textos a través de informantes locales convocados por el jefe de cantón, que, a su vez, actuaba siguiendo las órdenes del comandante de círculo. Así, hombres, mujeres, ancianos y niños eran enviados a la presencia del etnólogo francés para narrar los cuentos orales que conocían y éste les retribuía en función de la extensión e interés del relato. El mismo Hampâté Bâ fue seleccionado como informante y su nombre figura al final de algunos cuentos. Sin embargo, como explica Hampâté Bâ en sus memorias, aunque el que firmaba como autor de la obra fuese Equilbecq, la persona que se encargaba de recoger, traducir y redactar los textos en francés era Wangrin? maestro de la escuela de Bandiagara y traductor del comandante de círculo:

\footnotetext{
${ }^{4}$ El fondo de documentación de Hampâté Bâ se encuentra actualmente en el IMEC (Institut Mémoires de l'Édition Contemporaine).

${ }^{5}$ El Instituto Francés de África Negra fue la institución científica creada por el régimen colonial que cambió de nombre tras las independencias a Instituto Fundamental de África Negra.

${ }^{6}$ François-Victor Equilbecq (1913-1916) Essai sur la littérature merveilleuse des Noirs suivi des Contes indigènes de l'Ouest africain français, Leroux, París.

${ }^{7}$ Wangrin inició su carrera como moniteur d'enseignement indigène en la escuela colonial en Bandiagara, ciudad en la que tuvo la oportunidad de conocer al joven Hampâté Bâ. Entre los variados puestos que ocupa dentro de la administración colonial, uno de ellos es el de ayudante de Equilbecq en
} 
Chaque conte retenu était payé à l'informateur dix, quinze ou vingt centimes, selon sa longueur ou son importance. Au début, Wangrin les traduisait à $\mathrm{M}$. Equilbecq qui prenait des notes. Mais bientôt ce dernier se déchargea sur lui du soin de recueillir directement la plupart des textes. Wangrin rédigea une première traduction en français, puis la communiquait à M. Equilbecq, lequel y apportait éventuellement des corrections ou des modifications de son cru. Il devait publier une grande partie des contes recueillis [...] Il n'est pas sans intérêt de savoir que Wangrin en a été l'un des principaux rédacteurs. Son nom est cité dans la plupart des contes, précédé de la mention "traduit" par ou "interprété par" (Bâ, 1991: 346).

Hampâté Bâ no solamente ofrece un testimonio del papel del dinero como estimulante para la investigación etnológica, sino que, también deja entrever la posición de subalterno que ocupaba Wangrin, quien, sin embargo, era el que realizaba el grueso del trabajo de redacción de los textos. Hampâté Bâ no se muestra indiferente a la configuración del campo científico del saber colonial, en el que persistía una clara separación entre la función de los africanos y de los europeos. Aunque Wangrin figure como informante en una gran parte de los textos, éste no puede alcanzar la posición de autor, sino que pasará a la historia como un "simple maillon dans la chaîne de production scientifique" (Aggarwal, 1999: 220) ya que el reconocimiento científico es otorgado al autor europeo que ha realizado el trabajo de presentación de los textos.

Desde mediados del siglo XIX la biblioteca colonial recoge y actualiza la episteme (Foucault, 1971) que posibilita a los europeos justificar la conquista y la colonización del interior del territorio africano. La percepción que se había tenido en Europa de África y de los africanos durante siglos ${ }^{8}$ permite construir sin problemas una ideología colonial cuya función última era la de establecer unos determinismos internos y externos que legitimasen la incursión europea en África. Dicha ideología colonial se difunde activamente entre la población a través de distintos medios: discursos parlamentarios, obras teóricas, prensa, grabados populares, manuales escolares, exposiciones coloniales y literatura exótica. Como afirma Todorov, "le discours esclavagiste, puis colonialiste [...], n'est pas le simple effet d'une réalité économique, sociale et politique, il en est aussi une des forces motrices" (en Saï, 2005 [1980]: 8).

Tras siglos de construcción de una imagen profundamente desvalorizante de los africanos en el imaginario europeo, la promoción de la empresa colonial francesa

su misión etnológica. Precisamente la única novela escrita por Hamâté Bâ será la biografía de este polifacético personaje: L'Étrange destin de Wangrin (1973).

${ }^{8} \mathrm{La}$ identidad del africano fue fijada en función de unos cánones que habían sido instituidos y admitidos como legítimos en el interior del discurso europeo (Mangeon, 2010: 13-37). En Europa se fabricó durante siglos una biblioteca que construyó un mundo negro opuesto al mundo occidental. La invención de una retórica de la alteridad en torno a los africanos comienza en la obra del historiador griego Herodoto y se difunde con fuerza a partir del Renacimiento europeo, época en las que las imágenes míticas y negativas que niegan cualquier aptitud intelectual a los habitantes de África, aparecen repetidamente en los textos de los viajeros y geógrafos europeos. 
hacia el interior del continente se apoya en argumentos de corte racista que podían ser admitidos sin grandes inconvenientes por la mayoría de la población. Los principios políticos y económicos favorables a la empresa colonizadora de Francia se basaban fundamentalmente en la creencia de que los africanos, debido a una inferioridad innata ${ }^{9}$, no eran capaces de explotar las reservas de materias primas de las que disponían en sus territorios, lo cual justificaba plenamente la intervención europea (Cohen, 1981: 16; Mouralis, 1981: 20; Taguieff, 1998: 62).

La misión civilizadora del hombre blanco occidental en los territorios africanos encontró un apoyo importante en argumentos pretendidamente científicos que se basaban en el pensamiento pseudo-evolucionista y racista que se había desarrollado a lo largo del siglo XIX y que continuó siendo operativo durante las primeras décadas del siglo XX. Durante el siglo XIX científicos como Paul Broca, fundador de la "Société d'anthropologie" de París, Julien-Jospeh Virey, reputado médico y antropólogo, o el naturista Georges Cuvier, defendieron en sus escritos una correspondencia evidente entre inteligencia, temperamento activo y raza blanca (Mangeon, 2010: 34). En 1817, tras haber diseccionado a la tristemente célebre Venus Hotentote, los profesores de zoología del Museo Nacional de Historia Natural de París, Henri de Blainville y Geoffroy Saint-Hilare, afirmaron haber encontrado el eslabón perdido entre "la dernière race de l'espèce humaine, ou la race nègre, et la première des singes, ou l'ourang-outan" (Cf. Fauvelle-Aymar, 2002: 325-326). La raza negra era científicamente animalizada a partir de una muestra femenina, y esta disección conducía a continuación a la atribución de ciertos rasgos psicológicos. En 1893 el sociólogo francés Gustave Le Bon sostiene en su obra Lois psychologiques de l'évolution des peuples, cuya decimoquinta edición aparece en 1919, que "chaque race possède une constitution mentale aussi fixe que sa constitution anatomique" (Cfr. Taguieff, 1998: 62). Según Le Bon, en el devenir de la historia, la raza y sus características psicológicas indisolubles eran los elementos determinantes que habían guiado la evolución de los pueblos. Las incorrectas aplicaciones del darwinismo que realizaron autores como Le Bon influyeron notablemente en los autores que defendían la ideología colonial.

De esta manera, en el imaginario social se impuso la idea de que los africanos colonizados se encontraban en un estado de evolución inferior y que, por lo tanto,

\footnotetext{
${ }^{9}$ Albert Sarraut, ministro de las colonias de 1920 a 1924 y de 1932 a 1933 , sigue esta línea argumentativa en su libro Grandeur et servitude coloniale: "La nature a distribué inégalement, à travers la planète l'abondance et les dépôts de ces matières premières; et tandis qu'elle a localisé dans cette extrémité continentale qui est l'Europe le génie inventif des races blanches, la science de l'utilisation des richesses naturelles, elle a concentré les plus vastes réservoirs de ces matières dans les Afriques, les Asies tropicales, les Océanies équatoriales [...] Faut-il laisser en friche, faut-il abandonner aux ronces de l'ignorance ou de l'incapacité des immenses étendues incultes d'où ces nourritures peuvent jaillir?" (1931: 59).
} 
habían de ser conducidos al grado de civilización propio del hombre europeo. Esta mentalidad, que implicaba la existencia de un colonizado necesitado de los dones del colonizador, situaba a los africanos ante un doloroso dilema: intentar asimilarse al modelo occidental planteado por los colonos europeos, proceso propuesto como la única posibilidad de afirmación identitaria valorizante, o aislarse en unas tradiciones que eran percibidas como algo obsoleto y anquilosado. Sin embargo, como revelaron autores como Césaire (2004 [1955]) o Memmi (1985 [1966]), en realidad la disyuntiva que planteaba el colonizador era falsa, ya que la asimilación del africano al europeo hubiese llevado a una situación de igualdad que habría acabado con la justificación del régimen colonial. En realidad, la ideología forjada por el colonizador reposaba en una profunda contradicción: para justificar la empresa colonial tenían que exaltar la misión civilizadora de Occidente y la política de asimilación, pero al mismo tiempo, para conservar la iniciativa política y social, el colonizador tenía que subrayar la incapacidad del colonizado de alzarse a su mismo rango y asimilarse a su cultura.

La legitimidad del poder colonial reposaba, pues, en que los africanos aceptasen y asimilasen una versión degradada de su identidad, como indica Memmi:

Souhaité, répandu par le colonisateur, ce portrait mythique et dégradant finit, dans une certaine mesure, par être accepté et vécu par le colonisé. [...] La caractérisation et le rôle du colonisé occupent une place de choix dans l'idéologie colonisatrice; caractérisation infidèle au réel, incohérente en elle-même, mais nécessaire et cohérente à l'intérieur de cette idéologie. Et à laquelle le colonisé donne son assentiment, troublé, partiel, mais indéniable (1985 [1966]: 196).

Gounongbé (1995) señala que el objetivo de la ideología colonial era precisamente expulsar al individuo de su realidad y provocar el deseo de una asimilación ilusoria. Para lograrlo, era necesario difundir una percepción desvalorizante de la cultura africana que implicase que los nativos sintieran la necesidad de asumir una cultura diferente a la propia. El método principal de esta tarea civilizadora se basaba en la disuasión y en la persuasión: "dissuader l'Africain de ce qu'il est, de sa culture, et le persuader de la nécessité d'une autre culture afin de qu'il devienne un civilisé" (Gounongbé, 1995: 81).

Así, el hecho de transmitir un saber que justificase el tipo de relación que se había establecido entre Francia y sus colonias y que se opusiera a las interpretaciones que los africanos habían creado sobre su propia historia, vehiculada a través de la oralidad, se convertía en una prioridad. Las palabras de Georges Hardy, inspector de educación en África Occidental Francesa, acerca de los programas de las escuelas de las colonias, son ilustrativas en este sentido:

Les indigènes de nos colonies africaines ne nous ont point attendu pour se donner une histoire et des historiens [...]. Je conviens bien volontiers que cette histoire ne rappelle en rien les ouvrages couronnés par l'Institut et que ces historiens ressemblent singulièrement à des charlatans; mais ils existent, ils sont écoutés, ils disposent, si nous n'y prenons garde, d'une influence que Michelet n'a jamais connue (Hardy, 1917: 238). 
Amadou Hampâté Bâ no podía mostrarse indiferente a este régimen conceptual ni a la configuración del campo científico dominante en la época colonial. Consciente de los intereses creados en torno a la definición exógena de la identidad africana, Hampâté Bâ construye una obra en la que el autor reclama su derecho a revelar una imagen de las culturas de África del Oeste que se contraponga a los prejuicios difundidos por la ideología colonial, ofreciéndonos así una visión personal de su propia realidad vital y cultural.

Este proceso de aculturación en el que los referentes propios de la sociedad africana van diluyéndose en una nueva sociedad construida artificialmente, se efectúa sobre todo a través de la educación escolar puesta en marcha por la administración colonial. Cada cultura posee unos procesos de aprendizaje transmitidos de generación en generación que dotan a las personas de instrumentos suficientes para asegurar su socialización, de este modo, dentro de una cultura determinada la construcción de la personalidad del individuo dependerá en gran medida de su integración en un sistema coherente de representaciones colectivas que conformarán un entramado social y funcional. Los procesos educativos que operan dentro de cada cultura contribuirán de manera significativa a lograr una sociabilización adecuada y minimizarán el riesgo de desórdenes psicológicos. Como explica Gounougbé:

L'information qui véhicule une culture aurait "des effets sécurisants". C'est elle en effet qui permet d'appréhender le monde extérieur: elle permet à l'individu de poser des objectifs généraux et opérationnels de vie et de rechercher en conséquence les moyens adéquats pour les atteindre; elle participe au processus d'acceptation emphatique de l'environnement dans lequel on évolue et de l'acceptation de soi comme élément intégré à cet environnement. [...] La culture fournit également des modèles, c'est-à-dire un ensemble d'opérations mentales ou motrices, qui suivent une certaine propédeutique et les schémas de référence d'ordre éthique ou esthétique (1995: 26).

Si las culturas aparecen como una suma de actitudes de las que el hombre se sirve para aprehender su entorno vital, los cambios que se producen en el contexto social que rodea al individuo pondrán en jaque su propia cultura y su funcionalidad. En el caso de Hampâté Bâ, como en el de muchos autores que nacen y se forman en la época colonial, la cultura de la que proviene y en la que se educa antes de entrar en la escuela francesa, es un sistema cuestionado y desvalorizado por la cultura del colonizador. Las estructuras sociales de las sociedades africanas precoloniales son radicalmente modificadas con la instalación de la administración colonial francesa en África del Oeste y dejan de ser operativas dentro del nuevo contexto político y administrativo. Como consecuencia de ello, las jerarquías de estos regímenes dejan de ser efectivas y la nueva manera de ocupar un puesto socialmente relevante pasa por el aprendizaje de la lengua del colonizador y la inserción en el nuevo sistema administrativo colonial puesto en marcha por el gobierno francés. Hampâté Bâ es plenamente consciente de esta situación de ruptura que se genera a partir de la imposición del régimen colonial:

La rupture dans las transmission des connaissances d'une génération à l'autre s'accentua avec la lutte de l'administration contre les écoles coraniques et l'effort de scolarisation en langue 
française. Mais la grande cassure se produisit à l'occasion de la guerre de 1914. [...] D'un seul coup, les vieux maîtres furent privés de la plupart des élèves qui auraient pu continuer leur œuvre et assurer à leur tour la transmission et la sauvegarde du patrimoine culturel. [...] Traumatisme culturel, encore, le phénomène d'acculturation qui, par la suite, marqua tous ces de nos jeunes qui étudièrent dans les universités occidentales, creusant ainsi entre nos intellectuels et la masse africaine un fossé de plus en plus grand. [...] Traumatisme culturel, enfin, ce lent travail de dépersonnalisation qui s'accomplit au cours de décennies, au point que les Africains en arrivèrent à douter de leurs propres valeurs et ne concevoir l'évolution ou le progrès qu'à travers l'imitation totale des anciens colonisateurs, et dans tous les domaines (Hampâté Bâ entrevistado por Philippe Decraene, Le Monde, suplemento ${ }^{\circ}$ 11427, 25 octubre 1981/ Cfr. Decraenne, 2005: 324).

Partiendo de una clara percepción del hecho colonial y de sus consecuencias, Hampâté Bâ emprende una tarea de reivindicación de su identidad africana, personal y colectiva, que constituye la motivación final de toda su obra. Desde su primera obras, L'empire peul du Macina y Tierno Bokar, le sage de Bandiagara, publicadas al amparo de coautores europeos, Hampâté Bâ elige como ejes temáticos la revalorización de la historia del África del Oeste, de la que él mismo forma parte, y la reivindicación de una figura fundamental en su formación, su maestro Tierno Bokar, víctima del ostracismo de la administración francesa. Tras estos dos primeros trabajos, Hampâté Bâ se dedica a la publicación de una serie de relatos iniciáticos peuls ${ }^{10}$ que recoge de los fondos orales que todavía circulan en el África Occidental Francesa. Siendo consciente de que la cultura oral define y constituye la identidad africana, Hampâté Bâ entiende la tarea urgente de su conservación como una vía de revalorización de la cultura africana y una manera de dotar a los africanos de unas referencias propias fundamentales para lograr un autoreconocimiento identitario positivo. Tras la publicación de Koumen (1961) y Kaïdara (1969), relatos iniciáticos recogidos de la cultura peul, Hampâté Bâ publica en 1973 L'Étrange destin de Wangrin, novela que relata la accidentada biografía del maestro de la escuela colonial de Bandiagara que acabará convirtiéndose en un rico hombre de negocios capaz de rivalizar con los comerciantes europeos. Otro gran relato iniciático peul, Njeddo-Dewal, mère de la calamité, es publicado por Hampâté Bâ en 1985, obra a la que le sigue en 1987 la colección de cuentos $L a$ poignée de poussière, contes et récits du Mali.

Autor de numerosas conferencias, artículos y ensayos sobre la cultura africana, al final de su vida Hampâté Bâ se dedica a preparar los dos tomos de sus memorias ${ }^{11}$ que aparecen póstumamente y que transmiten una biografía apasionante en la que confluyen todos sus intereses vitales. Póstumamente aparecen también los Contes initiatiques peuls (1993b), Petit Bodiel et contes de la savane (1993a), Il n'y a pas de petite querelle (1999) y Contes des sages d'Afrique (2004), colecciones de

${ }^{10}$ Koumen (1961) y Kaïdara (1969). En 1974 Bâ publica L'Éclat de la grande étoile suivi du Bain rituel, en 1976 Petit Bodiel, y en 1985 Njeddo-Dewal, mère de la calamité.

${ }^{11}$ Amkoullel, l'enfant peul (1991) y Oui, mon commandant! (1994). 
cuentos que Hampâté Bâ había dejado al cuidado de su albacea literaria Helène Heckmann.

Nos acercaremos muy someramente a las principales obras del autor elaboradas a través de materiales provenientes de la oralidad ${ }^{12}$ para determinar cuál es el sentido que encuentra Hampâté Bâ en la utilización de estas fuentes. En 1955, tras haber escrito varios artículos y un relato ${ }^{13}$, Hampâté Bâ publica su primer libro, L'Empire peul du Macina (1818-1853), cuya autoría comparte con Jacques Daget, director del IFAN de Diafarabé. L'Empire peul du Macina es una crónica histórica del Imperio Peul de Macina y refleja la época de esplendor de este reino islámico que se extendió en las riveras del Níger y conquistó los territorios de sus vecinos bambaras, ardos y tuaregs. La obra no sólo pretendía mostrar la existencia de estados africanos sólidos y florecientes previos a la colonización francesa, sino que revelaba que los habitantes del África del Oeste poseían una historia y una memoria propia que había sido conservada a través de la oralidad.

Hampâté Bâ no es el único africano que trabajando dentro de las instituciones coloniales lleva a cabo investigaciones enmarcadas en el ámbito de la etnología ${ }^{14}$, sin embargo, fue el autor de la primera obra historiográfica basada en las informaciones extraídas de los testimonios orales almacenados en la memoria de los detentores de la historia africana. L'Empire peul du Macina es una obra de erudición elaborada tras un extenso trabajo de campo llevado a cabo en el territorio del antiguo Imperio peul de Macina para recoger testimonios orales. A partir de su puesto en el laboratorio del IFAN en Diafarabé y con el apoyo de su director Jacques Daget, Hampâté Bâ recorrió la zona durante dos años para realizar entrevistas a informantes cualificados ${ }^{15}$, entre los que se encuentran autoridades religiosas musulmanas, tradicionalistas, notables y descendientes de las personas que habían protagonizado la historia del Imperio peul de Macina.

Tras un intenso trabajo a partir de las informaciones recogidas para poder verificar su fiabilidad, ochenta testimonios fueron considerados válidos $\mathrm{y}$, a partir de ellos, se redactó el manuscrito de L’Empire peul du Macina publicado por el

\footnotetext{
${ }^{12}$ Dada la limitación de espacio nos referiremos al Empire Peul du Macina y a los cuentos iniciáticos peuls publicados por Hampâté Bâ.

13 "Notice sur Maghama et le canton du Littama" en Bulletin de l'IFAN (1939), Kaïdara, presentado y comentado por el profesor Monod, (Prix littéraire de l'Afrique occidentale française en 1943), "Les trois pêcheurs bredouilles (conte bambara)" en Notes africaines (1944), "Poésie peule du Macina" en Présence Africaine, $\mathrm{n}^{\circ}$ 8-9 (1950), "Note sur la migration des villages Sambourou" en Bulletin de l'IFAN (1951).

${ }^{14}$ A parte del caso de Paul Hazoumé, Moussa Travelé había publicado en 1919 Petit manuel français-bambara y en 1923 Proverbes et contes bambaras, ambos en la Librairie orientaliste Paul Geuthner. Dim Delobsson publica en 1933 L'Empire du Mogho-Naba (París, Editorial DomatMontechrestien) y en 1934 Les secrets des sorciers noirs (París, Librairie Emile Nourry), ambas obras son prologadas por Robert Randau.

${ }^{5} \mathrm{La}$ lista de los principales informadores, su procedencia y su posición social, está incluida en el “Avant-propos” del libro (1955: 14-15) firmado por Amadou Hampâté Bâ y Jacques Daget.
} 
IFAN en 1955. La elaboración de la crónica del Imperio peul de Macina correspondía a una voluntad de demostrar que la historia oral africana contenía informaciones válidas que podían ser objeto de un estudio científico. Valiéndose de su posición de "auxiliar indígena" dentro del IFAN, Hampâté Bâ se empeña en dignificar la historia africana y lograr que ésta pase a formar parte de la historia universal, intentando superar el etnocentrismo europeo que tiende a identificar la historia del continente blanco con la única historia posible. Se trata al mismo tiempo de recuperar la memoria histórica de los pueblos conquistados por Francia y dar a conocer un modo de civilización que poco tenía que ver con las ideas comunes acerca de las poblaciones de África que habían puesto en pie los prejuicios racistas.

L'Empire peul du Macina puede ser entendida como una tarea de conservación de los testimonios orales que componen la memoria histórica de un pueblo, pero también como una reescritura de la historia desde el punto de vista de los vencidos o los dominados, que alcanzan el derecho a la palabra a través del empeño de una persona implicada en el mismo devenir histórico. La afirmación que realiza Hampâté Bâ en el "Avant-propos" de la obra: "Nous avons cherché avant tout à respecter la façon dont les indigènes racontent eux-mêmes leur histoire" (1955: 13), nos muestra que estamos ante un proyecto de revalorización identitaria colectiva que reivindica una visión africana de la historia dentro del centro de producción del saber colonial.

Así, Hampâté Bâ se aleja de los patrones de la ciencia colonial y activa una manera de concebir la historia desde el punto de vista africano, haciendo que los testimonios orales emitidos por las autoridades de la sociedad africana autóctona alcancen un estatus desconocido hasta el momento. Como afirma Aggarwal (1999: 203), L'Empire peul du Macina es un verdadero manifiesto histórico ya que muestra por primera vez cómo y de qué manera los africanos se piensan ellos mismos en relación con los momentos fundadores de su pasado.

Tras escribir una obra dedicada a la biografía y a las enseñanzas de su maestro espiritual, Tierno Bokar, le sage de Bandiagara ${ }^{16}$, Hampâté Bâ publica junto a Germaine Dieterlen Koumen (1961), texto iniciático de los pastores peuls, al que le seguirán otros importantes relatos iniciáticos, Kaïdara (1969), publicado junto a Lilyan Kesteloot, y L'éclat de la grande étoile (1974), coeditado con Lilyan Kesteloot, Christiane Seydou y Alpha Ibrâhîm Sow, en edición bilingüe peulfrancés.

A partir de la publicación de los cuentos iniciáticos peuls, Hampâté Bâ alcanza una posición autorial que le permite codearse con los africanistas europeos más prestigiosos y, al mismo tiempo, figurar como autor de importantes textos orales africanos recogidos de su propia tradición. Dichas obras cuentan con un extenso

${ }^{16}$ Este es el título de la primera versión de la obra publicada junto a Marcel Cardaire, oficial francés encargado de asuntos islámicos. En 1980 aparece una nueva versión de la obra titulada Vie et enseingnement de Tierno Bokar en la que figura como único autor Amadou Hampâté Bâ. 
aparato de notas explicativas acerca de la interpretación de los textos elaborado por Hampâté Bâ y con unas cuidadas introducciones, en las que el autor africano participa ofreciendo numerosas informaciones acerca de la sociedad peul. De este modo, Hampâté Bâ no sólo aparece como el responsable de la versión del texto peul y de su traducción al francés, sino que alcanza igualmente una posición dentro del campo científico del africanismo que le permite ser una fuente válida de informaciones que atañen a su propia cultura.

Por otra parte, las ediciones de los cuentos peuls que se van sucediendo en el tiempo nos revelan una trayectoria en la que Hampâté Bâ interviene cada vez más en la elaboración de los relatos, que van evolucionando de ediciones científicas a versiones cada vez más literarias en las que el autor juega un papel preponderante (Mouralis, 2007: 234). En este mismo sentido, Christiane Seydou (2005: 70) afirma que los textos iniciáticos peuls publicados por Hampâté Bâ son interesantes tanto por su contenido, como por su estilo, que refleja el paso de una cultura de expresión oral a una recreación literaria escrita y personal. Según Seydou, los cuentos iniciáticos peuls de Hampâté Bâ no sólo nos informan sobre el pensamiento y la visión del mundo de los pueblos de África Occidental, sino que, además, inauguran una tipología literaria en la creación literaria africana moderna, ya que "ils inaugurent en effet un genre et un style originaux en donnant une expression écrite et personnelle à ce qui était une tradition orale et collective" (2005: 71).

En cuanto al contenido, si la mayoría de los europeos que se habían acercado a la literatura oral africana habían privilegiado en sus compilaciones el cuento breve de animales, género que parecía propio de una sociedad que había sido percibida bajo el prisma de la infantilización, Hampâté Bâ recoge y publica un tipo de textos que titula como "contes initiatiques" pero que, sin embargo, no podemos identificar con el esquema de lo que consideramos cuento popular, ya que su forma es mucho más compleja. Los "contes initiatiques" pertenecen a un tipo de texto de la literatura peul denominado jantol $^{17}$, género constituido por relatos de una gran extensión en el que intervienen personajes humanos y fantásticos y que poseen una clara vocación didáctica o iniciática. El jantol es un género narrativo que incluye un complejo contenido simbólico que sobrepasa el significado inmediato del texto y que no es accesible a todo tipo de público. El narrador del jantol suele ser un adulto experimentado en el arte de contar que puede desarrollar o abreviar ciertas partes del relato ${ }^{18}$ pero, sin embargo, no le es permitido variar el esquema principal que

\footnotetext{
${ }^{17}$ La traducción del término jantol es "histoire digne d'être rapportée" (Seydou, 2005: 71). El jantol puede ser recitado en verso con una cadencia rápida, entonces se denomina mergui, o en prosa, recibiendo la denominación de fulfude maw'nde (Bâ, 1994: 12).

${ }^{18}$ Estas extensas narraciones pueden incluir en su desarrollo secuencias o motivos pertenecientes al repertorio de cuentos de África del Oeste e incluso cuentos enteros que al integrarse en una narración diferente adquieren un nuevo sentido.
} 
estructura el relato, ya que las etapas, los símbolos, los hechos significativos y las fórmulas rituales del jantol no deben ser alterados. Estos textos desarrollan un recorrido lleno de pruebas progresivas que dan acceso al conocimiento oculto reservado al protagonista que es capaz de llegar hasta el final de la iniciación y, al mismo tiempo, transmiten estas mismas enseñanzas al destinatario que es capaz de escuchar y comprender el sentido último del texto.

El mismo Hampâté Bâ insiste en diversas ocasiones en el carácter pedagógico del contenido de los "contes initiatiques" y orienta su recepción en este sentido. Para el autor, la vocación didáctica constituye la esencia de dichos relatos:

Dans la société traditionnelle chaque jantol est comme un livre que le Maître récite et commente. Le jeune, lui, doit écouter, se laisser imprégner, retenir le conte et, autant que possible, le revivre en lui-même. On lui recommande (comme pour Kaïdara) de revenir sans cesse au conte à l'occasion des événements marquants de sa vie. Au fur et à mesure de son évolution intérieure, sa compréhension se modifiera, il y découvrira des significations nouvelles. Souvent telle preuve de sa vie l'éclairera sur le sens profond de tel ou tel épisode du conte; inversement, celui-ci pourra l'aider à mieux comprendre le sens de ce qu'il est en train de vivre (Bâ, 1994: 16).

El género oral elegido por Hampâté Bâ, contiene una de las temáticas predilectas del autor, a saber, demostrar que la cultura africana poseía un complejo sistema educativo basado en unos presupuestos que podían seguir siendo considerados válidos y operativos. Si las colecciones de literatura oral africana realizadas por autores europeos durante la época colonial habían compilado preferentemente textos cortos, fácilmente repertoriables y accesibles al gran público, Hampâté Bâ elige un género oral diferente que nos muestran una visión más completa de los africanos y de sus estructuras sociales. Siguiendo la estela de Marcel Griaule, Hampâté Bâ nos revela una visión muy elaborada de las sociedades de África Occidental, pero, a diferencia del etnólogo francés, Hampâté Bâ moldea los relatos orales de manera personal y no los considera piezas "museables" alejadas de la sociedad sino que insiste en sus amplias posibilidades pedagógicas y educativas ${ }^{19}$. Para Hampâté Bâ, la oralidad es una parte consustancial de la identidad de los pueblos africanos que determina un modo de aprendizaje propio; como indica Moura, Hampâté Bâ desarrolla "an epistemological point of view on orality, whereas Senghor had developed a metaphysical one" (2006: 93).

\footnotetext{
${ }^{19}$ Mouralis afirma a este respecto: "Hampâté Bâ redonne au sujet toutes ses prérogatives, dans une perspective tout à fait différente de celle de Griaule qui a eu toujours tendance, même s'il fut probablement le premier anthropologue à s'effacer devant la parole africaine pour se mettre à son écoute, à considérer cette parole comme un tout qu'il fallait recueillir tel quel. C'est pourquoi, on peut considérer qu'il y a une dimension proprement philosophique dans l'œuvre de Hampâté Bâ puisqu'elle ne cesse de mettre l'accent sur la nécessité d'interpréter la tradition, ce qui, étymologiquement, est une contradiction, mais bien évidemment, une contradiction féconde" (2007: 241).
} 
Hampâté Bâ cree firmemente en que el corpus oral africano guarda enseñanzas útiles e interesantes que deben ser comunicadas al resto del mundo y que pueden formar parte del acervo cultural universal, además de ser una fuente de divertimento y placer estético. En este sentido Hampâté Bâ considera que la tradición oral puede ser considerada como una gran escuela de la vida abierta a todas las disciplinas:

La tradition orale, c'est la grande école de la vie; elle traite de la religion, des sciences de la nature comme de la connaissance des minerais, de la pharmacopée et de la médecine, de l'initiation professionnelle, de l'histoire, des jeux et des loisirs, de l'amour et de la mort. Liée au comportement concret de l'homme en société, la connaissance dans les sociétés africaines orales n'est donc pas abstraite et autonome par rapport à la vie (Bâ, en Ki-Zerbo, 1980: 100).

Los cuentos iniciáticos nos hablan de la posición de la persona dentro de la sociedad y de cuáles son los valores y comportamientos que cada individuo debe de fomentar en sí mismo para convertirse en un miembro útil e integrarse de manera positiva dentro de su comunidad. En la mayoría de las culturas de África del Oeste este proceso de integración se realizaba a través de las diversas iniciaciones que puntuaban la existencia de cada persona, los valores que la persona debía asumir al superar una nueva iniciación estaban fundamentados en la escucha, la atenta observación del entorno y el autocontrol de los propios impulsos. Según las normas no escritas de las civilizaciones orales, una persona capaz de observar estas reglas morales y sociales se convertía en un miembro activo de la comunidad cuya existencia beneficiaba a todo el grupo. Tras la colonización europea y el desmantelamiento de las estructuras sociales propias de los pueblos colonizados Hampâté Bâ recuerda que estas sociedades poseían un rico entramado social construido a través de diferentes procesos de integración, y sitúa la oralidad, y la transmisión de los conocimientos a través de ésta, en el centro de este sistema.

La obra de Hampâté Bâ refleja un esfuerzo continuo en mostrar los cimientos de la identidad africana sin ceder, sin embargo, a la tentación de la esencialización idealizante. Si la obra de Hampâté Bâ parece desafiar las clasificaciones, y el autor aparece al mismo tiempo como un recopilador de tradiciones orales, historiador y antropólogo, novelista y biógrafo, es porque en realidad lo que confiere una profunda coherencia a la obra es el interés de Hampâté Bâ por entender, interpretar y difundir una cultura africana de la que él es parte integrante. Las múltiples facetas bajo las que se presenta el autor a través de su obra no pueden ser comprendidas o explicadas sino como la toma de posición de un autor que partiendo de un rol auxiliar dentro de la sociedad colonial logra alcanzar un lugar significativo que le permite interpretar y dar a conocer su propia cultura. Entendiendo la identidad como la conciencia y la asunción de unos modos de ser, pensar y actuar que dotan de significado y sentido a la vida de una persona (Álvarez-Muñarriz, 2011: 497), podemos afirmar que Hampâté Bâ se empeña en rescatar estos modos de pensar y actuar de las sociedades de África del Oeste a través de la recuperación y difusión de sus textos orales, con el objetivo de dar a conocer a un público universal una visión más completa y ajustada de los elementos constitutivos de una identidad 
africana que se contrapone a los prejuicios desvalorizantes difundidos durante siglos.

\section{REFERENCIAS BIBLIOGRÁFICAS}

Álvarez-Munárriz, L., (2011) "La compleja identidad personal" in Revista de Dialectología y Tradiciones Populares. Vol. LXVI, nº 2, pp. 407-432.

Aggarwal, K., (1999) Amadou Hampâté Bâ et l'africanisme. París, L'Harmattan.

Bâ, A. H., (1972) Aspects de la civilisation africaine. París, Présence africaine.

Bâ, A. H., (1973) L'Étrange destin de Wangrin. París, Union Générale d'Éditions.

Bâ, A. H., (1976a) Jésus vu par un musulman. Dakar-Abiyán, NEA.

Bâ, A. H., (1976b) Petit Bodiel. Dakar-Abiyán, NEA.

Bâ, A. H., (1980) Vie et enseignement de Tierno Bokar. París, Seuil.

Bâ, A. H., (1985) Njeddo-Dewal, mère de la calamité. Abiyán, NEA.

Bâ, A. H., (1987) La poignée de poussière, contes et récits du Mali. Abiyán, NEA.

Bâ, A. H., (1991) Amkoullel, l'enfant peul. París, Actes Sud.

Bâ, A. H., (1994) Oui mon commandant! París, Actes Sud.

Bâ, A. H., (1993a) Petit Bodiel et autres contes de la savane. Abiyán, NEI.

Bâ, A. H., (1993b) Contes intiatiques peuls. Abiyán, NEI.

Bâ, A. H., (1999) Il n'y a pas de petite querelle. Nouveaux contes de la savane. París, Stock.

Bâ, A. H., (2004) Contes des sages d'Afrique. París, Seuil.

Bâ, A. H. \& J. Daget, (1955) L'empire peul du Macina. Bamako, IFAN.

Bâ, A. H. \& G. Dieterlen, (1961) Koumen. Texte initiatique des pasteurs peuls. París, Cahiers de l'Homme.

Bâ, A. H. \& L. Kesteloot, (1969) Kaïdara, récit initiatique peul. París, Classiques Africaines.

Bâ, A. H. et al., (1974) L'Éclat de la grande étoile suivi du Bain rituel. París, Armand Colin.

Baumgardt, U. \& J. Dérive, (2008) Littératures orales africaines. París, Karthala.

Casanova, P., (1999) La République mondiale des lettres. París, Seuil.

Césaire, A., (2004 [1955]) Discours sur le colonialisme. París, Présence Africaine.

Cohen, W. B., (1981) Français et Africains. Les noirs dans le regard des Blancs 1530- 1880. París, Gallimard.

Decraene, Ph., (2005) "Les leçons de sagesse africaine de l'oncle Hampâté Bâ" in Touré, A. \& N. A. Mariko, Hampâté Bâ homme de science et de sagesse. Bamako, Nouvelles Éditions Maliennes, pp. 321-331.

Durand, J.-F., (2003) "Une vision de l'Afrique" in Interculturel Francophonies. $\mathrm{N}^{\mathrm{o}} 3-4$, pp. $9-20$.

Garnier, X., (2003) "Kaidara au miroir de nous-mêmes. Étude sur la dynamique du conte initiatique" in Interculturel Francophonies. № 3-4, pp. 69-83.

Gounongbé, A., (1995) La toile de soi. París, L'Harmattan.

Griaule, M., (1966) Dieu d'eau. Entretiens avec Ogotommêli. París, Fayard. 
Fauvelle-Aymar, F. X., (2002) L'invention du Hottentot, histoire du regard occidental sur les Khoisan, $X V^{e}-X I X^{e}$ siècles. París, Publications de la Sorbonne.

Foucault, M., (1971) L'ordre du discours. París, Gallimard.

Hardy, G., (1917) Une conquête morale, l'enseignement en AOF. París, ArmandColin.

Ki-Zerbo, J., (1980) Histoire Générale de l'Afrique, Vol. I. Paris. Unesco.

Mangeon, A., (2010) La pensée noire et l'Occident. París, Sulliver.

Memmi, A., (1985 [1966]) Portrait du colonisé. Portrait du colonisateur. París, Gallimard.

Moura, J. M., (2006) “Textual Ownership in L'Étrange destin de Wangrin (The fortunes of Wangrin) by Amadou Hampâté Bâ" in Research in African Literatures. Vol. 37, no 1, pp. 91-99.

Mouralis, B. (1981) Littérature et développement. Lille, Université de Lille-Honoré Champion.

Mouralis, B., (2007) L'illusion de l'altérité. París, Honoré Champion.

Saïd, E., (2005 [1980]) L'Orientalisme. París, Seuil.

Sarraut, A., (1931) Grandeur et servitude coloniale. París, Sagittaire.

Taguieff, P.A., (1998) La couleur et le sang. París, Éditions Mille et Une nuits.

Seydou, Ch., (2005) "Amadou Hampâté Bâ, écrivain peul” in Touré, A. \& N. A. Mariko, Hampâté Bâ homme de science et de sagesse. Bamako, Nouvelles Éditions Maliennes, pp. 69-78.

Spivak, G. Ch., (1988) "Can the subaltern speak?" in Nelson, C. \& L. Grossber, Marxism and the interpretation of culture. Urbana, University of Illinois Press, pp. 271-313. 